\title{
Rumen and milk odd- and branched-chain fatty acid proportions are minimally influenced by ruminal volatile fatty acid infusions
}

\author{
E. A. French, S. J. Bertics, and L. E. Armentano ${ }^{1}$ \\ Department of Dairy Science, University of Wisconsin-Madison, Madison 53706
}

\begin{abstract}
The objective of this study was to determine if ruminally infusing volatile fatty acid (VFA) increased concentration of their homologous odd- and branchedchain fatty acid (OBCFA) in rumen contents and milk. The influence of VFA on dry matter intake (DMI), blood metabolites, and blood insulin was also evaluated. Four mid-lactation cows were assigned to a $4 \times 4$ Latin square design with 48 -h periods. Infusion treatments were acetate $(\mathrm{AC})$, propionate $(\mathrm{PR})$, isovalerate (IV), and anteisovalerate (AIV). Infusions began $($ time $=0) 5.5 \mathrm{~h}$ before feeding at $17.4 \mathrm{mmol}$ of VFA/ min and were terminated at $18 \mathrm{~h}$. Infusions rates were well above physiological levels for IV and AIV. Surprisingly, the greatest differences in rumen OBCFA were increases in rumen liquid iso C15:0 and nonbranched C17:0 for AIV. In addition, infusing AIV increased anteiso $\mathrm{C} 15: 0$ and anteiso C17:0 in rumen solid contents. Infusing IV increased iso C15:0 in both rumen solids and milk. Propionate increased milk C15:0 and C17:0. Both gluconeogenic compounds, PR and AIV, had similar proportions of milk C15:0, which was greater than that obtained with AC and IV. Rumen and blood VFA were as expected, with increased concentrations of the VFA present in the infusate. At $23 \mathrm{~h}$, and consistently throughout infusions, DMI was similar for AC compared with PR and for AIV compared with IV. Both IV and AIV decreased DMI and energy balance; however, only IV increased plasma nonesterified fatty acids (121, 78, 172, and $102 \mathrm{mM}$ for AC, AIV, IV, and PR), increased $\beta$-hydroxybutyrate $(10.8,5.9,51.9,5.4$ $\mathrm{mg} / \mathrm{dL}$ for $\mathrm{AC}, \mathrm{AIV}, \mathrm{IV}$, and $\mathrm{PR}$ ), and reduced plasma glucose $(56.3,59.1,31.9$, and $64.3 \mathrm{mg} / \mathrm{dL}$ for AC, AIV, IV, and PR). Rumen and milk OBCFA responses were minimal following infusion of large amounts of IV and AIV, suggesting limited use of IV, and AIV for de novo OBCFA synthesis, either pre- or postabsorption. Minor increases in milk odd-chain fatty acids following large
\end{abstract}

Received August 11, 2011.

Accepted November 19, 2011.

${ }^{1}$ Corresponding author: learment@wisc.edu doses of ruminal PR support the presence of postabsorptive synthesis of these milk odd-chain fatty acids. Key words: odd- and branched-chain fatty acid, dairy cow, volatile fatty acid infusion, rumen

\section{INTRODUCTION}

Ruminant lipids contain nonbranched fatty acids with an odd carbon number and branched-chain fatty acids with an odd or even carbon number, collectively termed odd- and branched-chain fatty acids (OBCFA). Because these OBCFA are not usually found in animal feeds, the appearance of OBCFA in lipids of herbivores led Akashi and Saito (1960) to suggest that these FA arise from microorganisms populating the gut. The theory was supported by Keeney et al. (1962), who determined that OBCFA comprised the majority of total lipids within culturable rumen bacteria, further suggesting that milk OBCFA have the potential to estimate rumen microbial yield.

Bacterial branched-chain FA can be synthesized from branched-chain AA (BCAA) or extracellular branchedchain VFA (BCVFA; Kaneda, 1991). The BCAA Leu, Ile, and Val are incorporated into branched-chain FA intracellularly via deamination and decarboxylation into the acyl-CoA esters 3-methylbutyryl-CoA, 2-methylbutyryl-CoA, and isobutyryl-CoA, followed by elongation into branched-chain FA. Acyl-CoA esters can also be formed from BCVFA by fatty acid synthetase. The acylCoA esters are elongated into iso methyltetradecanoic acid, iso C15:0; iso methylhexadecanoic acid, iso C17:0 (from 3-methylbutyryl-CoA); anteiso methyltetradecanoic acid, anteiso $\mathrm{C} 15: 0$; anteiso methylhexadecanoic acid, anteiso $\mathrm{C} 17: 0$ (from 2-methybutyryl-CoA); iso tetradecanoic acid, iso $\mathrm{C} 14: 0$; and iso hexadecanoic acid, iso C16:0 (from isobutyryl-CoA). Formation from BCVFA, 3-methylbuyrate (isovalerate, IV), 2-methylbutyrate (anteisovalerate, AIV), and isobutyrate primarily occurs by the deamination and decarboxylation of BCAA, although BCVFA may also be synthesized through acyl transferases or fatty acid kinase activity (Kaneda, 1991). Amino acid catabolism in one species and use of released BCVFA by another species can result in conversion of BCAA to OBCFA, with transfer 
of BCVFA through the ruminal fluid space. The odd and nonbranched FA pentadecanoic acid (C15:0) and heptadecanoic acid (C17:0) are formed by the elongation of propionyl-CoA or valeryl-CoA (Kaneda, 1991).

Alterations of the OBCFA content of the rumen microbial mass can be due to a shift in microbial species as the innate OBCFA content differs across microbial species. Alternatively, within-species shifts in OBCFA pattern might be caused by altering the substrate pattern offered (Allison et al., 1962; Wegner and Foster, 1963; Allison and Peel 1971; Emmanuel, 1978).

Dewhurst et al. (2007) compared milk yields versus duodenal FA flows and measured greater secretion of C15:0, C17:0, and iso C17:0 in milk fat than could be accounted for solely by absorption. Milk yields greater than duodenal flow for a particular OBCFA could occur via several routes. The mammary gland could directly synthesize OBCFA, as observed previously when propionate (PR) was perfused into goat and cow udders and milk odd-chain FA increased (James et al., 1956; Massart-Leën et al., 1983). Other tissues have also demonstrated the ability to synthesize OBCFA from PR (Berthelot et al., 2001) and milk OBCFA could increase by incorporating OBCFA mobilized from other tissues.

Limited in vivo studies have observed the effects of VFA as FA precursors. The objective of the current study was to observe the effects of intraruminally infusing VFA in vivo on rumen fatty acid proportions and their appearance in milk. Intraruminal infusions of PR previously increased proportions of odd-chain FA in milk (Emmanuel and Kennelly, 1985; Rigout et al., 2003). Treatments in our present study included acetate (AC), PR, and the BCVFA AIV and IV. The effect of infusing VFA on DMI and the physiological state of the animals was also observed as mobilized FA from adipose tissue can influence milk OBCFA (Craninx et al., 2008). Infusing AIV and IV was expected to increase appearance of the respective rumen odd anteiso and iso FA via microbial synthesis that would be reflected in milk fat. As suggested previously (Vlaeminck et al., 2006a; Bessa et al., 2009), a lack of response in rumen OBCFA proportions from VFA infusions would indicate that changes in OBCFA result from alterations in the prevalence of microbial species present in the rumen, not by availability of extracellular VFA precursors.

\section{MATERIALS AND METHODS}

\section{Experimental Design, Cows, and Treatments}

Four multiparous, rumen-cannulated Holstein cows were randomly assigned to a single $4 \times 4$ Latin square with 48 -h periods. Each cow was fitted with a $10-\mathrm{cm}$ rumen cannula (Bar Diamond, Parma, ID) at least 1 mo before the start of period 1 of the Latin square. The Animal Care and Use Committee for the College of Agricultural and Life Sciences at the University of Wisconsin-Madison approved all animal procedures.

Animals were housed in tie-stalls with free access to water and fed a basal diet to meet the requirements set by the National Research Council (NRC, 2001). The diet was formulated for cows at 120 DIM, weighing 685 $\mathrm{kg}$, and producing $40 \mathrm{~kg}$ of milk with $3.6 \%$ milk fat and $3.0 \%$ true milk protein. The TMR contained, on a DM basis (g/kg of DM): 322 alfalfa silage, 298 corn silage, 305 concentrate mixture, 78 cottonseed, with supplemented vitamins and minerals. Cows were fed the basal diet for $18 \mathrm{~d}$ before the start of the first infusion period. Diets were fed once daily to allow for $10 \%$ refusals. Cows were $119 \pm 8$ DIM (mean \pm SD) and weighed $685 \pm 98 \mathrm{~kg}$ when assigned to the basal diet and were milked twice daily at 0330 and $1530 \mathrm{~h}$. At the start of the Latin square, cows averaged 137 DIM. Milk weights were recorded at each milking starting at the beginning of the 18-d adaptation period until the end of the Latin square experiment. Experimental treatments prepared for intraruminal infusion included AC (acetic acid, no. A-38P-20; Fisher Scientific, Fair Lawn, NJ), PR (propionic acid, no. W-292400; Sigma-Aldrich Co., Milwaukee, Wisconsin), AIV (2-methylbutyric acid, no. W-269506; Sigma-Aldrich Co.), and IV (isovaleric acid, no. W-310204; Sigma-Aldrich Co.). Although all solutions were approximately isomolar, only the AIV and IV treatments were isoenergetic. The experimental solutions were adjusted to a $\mathrm{pH}$ of 6.5 using a 3:1 (molar basis) ratio of an $\mathrm{NaOH}: \mathrm{KOH}$ solution.

Treatments were infused through $3 / 8$ " o.d. $\times 3 / 16$ " i.d. tubing (Fisher Scientific, Fair Lawn, NJ) and extended $30 \mathrm{~cm}$ into the rumen with holes spaced $2.5 \mathrm{~cm}$ apart on alternating sides of the tubing to distribute the solution more evenly within the rumen. Treatments were infused using peristaltic pumps (Mec-o-matic VSP-20; W. W. Grainger Inc., Lincolnshire, IL). Feed was removed and infusion of the experimental solutions commenced at $0400 \mathrm{~h}$ (time $=0 \mathrm{~h})$, and ended at 2200 $\mathrm{h}($ time $=18 \mathrm{~h})$. Relative to the start of infusions $(0 \mathrm{~h})$, feed was offered at $5.5 \mathrm{~h}$. Cows were infused with $15 \mathrm{~L}$ of a $1.25 \mathrm{M}$ solution at a rate of $17.4 \mathrm{mmol}$ of $\mathrm{VFA} / \mathrm{min}$. The measured amount of each VFA delivered varied slightly from the expected amount of $18.8 \mathrm{~mol}$ over the course of the entire infusion, and averaged 19.0, 19.3, 19.0 , and $18.3 \mathrm{~mol} / 18 \mathrm{~h}$ for AC, PR, AIV, and IV. The total energy infused into each animal was 4.05, 7.03, 12.88 , and $12.37 \mathrm{Mcal} / 18 \mathrm{~h}$ for AC, PR, AIV, and IV.

\section{Feed Sampling and Analysis}

Individual samples of the TMR offered, alfalfa silage, corn silage, concentrate mixture, and cottonseed were 
collected weekly starting in the first week of the adaptation period $(\mathrm{n}=4)$. Daily ort samples were collected throughout the experiment starting on $\mathrm{d}-3$ relative to the start of the first infusion period until the end of the fourth Latin square experimental period to measure DMI. Accumulated as-fed refusals were weighed and recorded at 9.5, 13.5, 17.5, and $23 \mathrm{~h}$ on the day of infusion. Dry matter was only determined on the whole-day refusals of each cow at the end of the infusion period. Feed and 23-h ort samples were dried at $60^{\circ} \mathrm{C}$ for 48 $\mathrm{h}$ in a forced-air oven, ground to pass a 1-mm screen (Wiley mill, Arthur H. Thomas, Philadelphia, PA). Individual ort samples and composited feed samples were then analyzed for DM, ash, CP, NDF, and individual FA concentration (Table 1). To calculate DMI, refusals were assumed to have the same DM concentration as determined at $23 \mathrm{~h}$.

Analytical DM was determined by drying feed and refusal samples at $100^{\circ} \mathrm{C}$ for $24 \mathrm{~h}$ (AOAC, 2006; method 934.01). Ash was determined by oven combustion at $600^{\circ} \mathrm{C}$ for $2 \mathrm{~h}$ (AOAC, 2006; method 942.05). Neutral detergent fiber was determined using heat-stable $\alpha$-amylase (Ankom Technology, Macedon, NY) with sodium sulfite following the method described by Van Soest et al. (1991). Results were corrected for ash concentration. This method was adapted for the Ankom ${ }^{200}$ fiber analyzer (Ankom Technology). Nitrogen content of the feeds was determined by micro-Kjeldahl analysis (AOAC, 2006; method 2001.11). The percentage of individual and total FA in feedstuffs were measured by gas-liquid chromatography (GLC) following isolation and methyl-ester formation (Sukhija and Palmquist, 1988). Feed fatty acid methyl esters (FAME) were analyzed on a PerkinElmer Clarus 500 (PerkinElmer, Norwalk, CT) using a WCOT fused silica, 100-m $\times$ 0.25-mm coating CP-Sil 88 for FAME capillary column (Chrompack 100m \#CP7489, Varian Inc., Walnut Creek, CA). Helium was used as the carrier gas, and injector and detector temperatures were $255^{\circ} \mathrm{C}$. Peaks were identified based on commercially bought individual FA and bacterial FAME mixtures from Supelco Inc. (Bellefonte, PA), Sigma Chemical Co. (St. Louis, MO), and Matreya Inc. (Pleasant Gap, PA). The OBCFA identified between all the standards used included iso

Table 1. Chemical composition of the individual feed ingredients and TMR

\begin{tabular}{|c|c|c|c|c|c|}
\hline Item & $\begin{array}{l}\text { Alfalfa } \\
\text { silage }\end{array}$ & $\begin{array}{l}\text { Corn } \\
\text { silage }\end{array}$ & $\begin{array}{c}\text { Concentrate } \\
\text { mix }\end{array}$ & Cottonseed & TMR \\
\hline $\mathrm{DM}, \mathrm{g} / \mathrm{kg}$ as fed & 523 & 311 & 933 & 932 & 489 \\
\hline $\mathrm{CP}, \mathrm{g} / \mathrm{kg}$ of $\mathrm{DM}$ & 191 & 83 & 153 & 236 & 153 \\
\hline $\mathrm{NDF}, \mathrm{g} / \mathrm{kg}$ of $\mathrm{DM}$ & 342 & 364 & 134 & 408 & 288 \\
\hline Ash, $\mathrm{g} / \mathrm{kg}$ of DM & 107 & 55 & 99 & 42 & 85 \\
\hline $\begin{array}{l}\text { Total FA, } \mathrm{g} / \mathrm{kg} \text { of } \mathrm{DM} \\
\text { FA, g/kg of DM }\end{array}$ & 13 & 17 & 15 & 170 & 27 \\
\hline C6:0 & $\mathrm{ND}^{1}$ & ND & 0.377 & ND & 0.119 \\
\hline $\mathrm{C} 8: 0$ & ND & ND & 0.063 & ND & 0.019 \\
\hline $\mathrm{C} 12: 0$ & 0.079 & 0.046 & 0.045 & ND & 0.054 \\
\hline $\mathrm{C} 13: 0$ & 0.056 & 0.022 & ND & ND & 0.024 \\
\hline Iso C14:0 & 0.059 & 0.034 & ND & ND & 0.030 \\
\hline C14:0 & 0.078 & 0.060 & 0.221 & 0.187 & 0.259 \\
\hline Iso $\mathrm{C} 15: 0$ & 0.116 & 0.020 & ND & 0.027 & 0.065 \\
\hline Anteiso C15:0 & ND & ND & ND & ND & ND \\
\hline C15:0 & 0.042 & 0.009 & ND & 0.007 & 0.022 \\
\hline Iso C16:0 & ND & ND & ND & ND & ND \\
\hline C16:0 & 2.904 & 2.946 & 3.870 & 4.787 & 6.723 \\
\hline Iso $\mathrm{C} 17: 0$ & 0.060 & 0.032 & ND & ND & 0.030 \\
\hline C16:1 cis-9 & 0.347 & 0.065 & 0.189 & 0.090 & 0.267 \\
\hline Anteiso C17:0 & ND & ND & ND & ND & ND \\
\hline C17:0 & 0.068 & 0.048 & 0.062 & 0.019 & 0.070 \\
\hline $\mathrm{C} 17: 1$ & 0.064 & 0.099 & ND & 0.007 & 0.054 \\
\hline C18:0 & 0.527 & 0.505 & 1.044 & 0.473 & 1.015 \\
\hline C18:1 total & 0.664 & 3.150 & 3.761 & 3.069 & 4.655 \\
\hline C18:2 n-6 & 2.358 & 6.525 & 3.539 & 8.087 & 9.955 \\
\hline C18:3 n-3 & 4.022 & 1.035 & 0.176 & 0.034 & 1.747 \\
\hline $\mathrm{C} 20: 0$ & 0.074 & 1.726 & ND & ND & 0.502 \\
\hline C20:1 & ND & 0.024 & 0.095 & ND & 0.038 \\
\hline $\mathrm{C} 22: 0$ & 0.196 & 0.092 & ND & ND & 0.092 \\
\hline $\mathrm{C} 20: 3 \mathrm{n}-6$ & ND & 0.051 & ND & ND & 0.014 \\
\hline $\mathrm{C} 22: 1$ & 0.523 & ND & ND & ND & 0.178 \\
\hline C20:4 & ND & ND & 0.161 & ND & 0.051 \\
\hline Unknowns C4-C22:6 & 0.764 & 0.512 & 1.401 & 0.214 & 1.015 \\
\hline
\end{tabular}

${ }^{1} \mathrm{ND}=$ not detected in sample. 
$\mathrm{C} 14: 0$, iso $\mathrm{C} 15: 0$, anteiso $\mathrm{C} 15: 0$, iso $\mathrm{C} 16: 0$, iso $\mathrm{C} 17: 0$, anteiso C17:0, C17:0, and C17:0 cis-9. The feed FAME samples were run using the following temperature program: initial column temperature was $50^{\circ} \mathrm{C}$ and increased to $190^{\circ} \mathrm{C}$ at $4^{\circ} \mathrm{C} / \mathrm{min}$ where it was held for a total run time of $150 \mathrm{~min}$. Helium flow was constant at $0.9 \mathrm{~mL} / \mathrm{min}$, split 60:1. The percentage total FA was calculated by adding each FA from C4:0 to C24:1.

\section{Blood Sampling and Analysis}

Blood samples were collected from the coccygeal vein or artery at 0 and $18 \mathrm{~h}$. Blood was separated into plasma for glucose, NEFA, BHBA, VFA analysis, and into serum for insulin analysis. Evacuated glass tubes for the collection of plasma contained $12 \mathrm{mg}$ of potassium oxalate and $15 \mathrm{mg}$ of sodium fluoride. Blood samples for plasma were kept on ice before centrifugation for 20 min at $920 \times g$ at $4^{\circ} \mathrm{C}$. Serum samples were allowed to clot at room temperature before centrifugation at 2,050 $\times g$ at $20^{\circ} \mathrm{C}$ for $20 \mathrm{~min}$.

Plasma samples were analyzed for glucose using an oxidase and peroxidase method (Karkalas, 1985) and NEFA using an HR Series NEFA-number 2 kit (Wako Pure Chemical Industries, Ltd. Richmond, VA; Novak, 1965). Plasma BHBA analysis followed the procedure by Gibbard and Watkins (1968). Serum was analyzed for insulin (Porcine insulin RIA kit PI-12K; Linco Research Inc., St. Charles, MO). Plasma VFA concentrations were determined in samples following the procedure by Remesy and Demigne (1974) with several modifications. Briefly, VFA were extracted from duplicate, $200-\mu \mathrm{L}$ plasma samples. One sample contained 20 $\mu \mathrm{L}$ of $14 \mathrm{~m} M$ isobutyrate as an internal standard and the other $20 \mu \mathrm{L}$ of distilled water. Distilled water was added at $20 \mu \mathrm{L}$ to the duplicate sample to maintain volume consistency. Anhydrous ethanol (Acros Organics, Morris Plains, NJ) was added at $1 \mathrm{~mL}$ to extract VFA. Samples were then centrifuged at $8,609 \times g$ for $3 \mathrm{~min}$, and the supernatant was transferred into a 13$\times 100-\mathrm{mm}$ culture tube. Samples were made alkaline by adding $20 \mu \mathrm{L}$ of $0.2 \mathrm{~N}$ sodium hydroxide (Fisher Scientific), briefly vortexed, and dried under air until a residue remained. Samples were frozen until analysis. Immediately before being injected into the gas-liquid chromatograph, samples were dissolved in $15 \mu \mathrm{L}$ of distilled water and $5 \mu \mathrm{L}$ of $25 \%$ (vol/vol) orthophosphoric acid.

Plasma samples were expected to contain isobutyrate (IB). To measure its presence, one sample was run with the IB internal standard (std) added and the other with distilled water added. The sample without the internal standard was used to calculate the ratio of IB to PR. Based on the similarity in retention times, the PR to IB ratio was used to estimate the basal concentration of IB in the std sample as follows:

$$
\text { Basal } \mathrm{IB}_{\mathrm{std}}=\left[\frac{\mathrm{IB}(\mathrm{mmol} / \mathrm{L})}{\mathrm{PR}(\mathrm{mmol} / \mathrm{L})}\right]_{\mathrm{water}} \times \mathrm{PR}(\mathrm{mmol} / \mathrm{L})_{\mathrm{std}} \text {. }
$$

The area representing the internal standard in std samples was estimated by subtracting the predicted basal concentration of IB from the total IB area. Resulting IB areas were used to estimate percentage sample recovery and correct other detected VFA (Table 2 ). Concentrations of individual VFA were measured on a Perkin Elmer Autosystem using a 4\% Carbowax $20 \mathrm{M}$ on $80 / 120$ mesh Carbopack B-DA, $1.8 \mathrm{~m} \times 2$ mm column (Supelco Inc.). Nitrogen was used as a carried gas, and the injector and the detector temperature were $200^{\circ} \mathrm{C}$. The column temperature was maintained at $160^{\circ} \mathrm{C}$ for $45 \mathrm{~min}$. Nitrogen flow was maintained at $24 \mathrm{~mL} / \mathrm{min}$. Identification of VFA peaks were based on a purchased external standard from Sigma Chemical Co. (St. Louis, MO).

\section{Rumen $\mathrm{pH}, \mathrm{VFA}$, and FA Analyses}

Rumen samples were obtained from 5 different locations within the rumen. Samples were collected at $18 \mathrm{~h}$. Rumen $\mathrm{pH}$ was determined immediately using a Cardy Twin pH meter (model \#B-213, Spectrum Technologies Inc., Plainfield, IL; Table 3). Rumen contents were brought back to the laboratory, where they were purged with $\mathrm{CO}_{2}$ and strained through 4 layers of cheesecloth into liquid (LIQ) and solid (SOL) phases. Two 1-mL aliquots of rumen liquid were added to microcentrifuge tubes containing $0.02 \mathrm{~mL}$ of $50 \% \mathrm{H}_{2} \mathrm{SO}_{4}$ acid for later VFA analysis. Following preparation, rumen VFA concentrations were measured by GLC (Supelco, 1998; Table 3). Nitrogen was used as the carrier gas. Gas flow rates and the temperature program were the same as described for blood VFA analysis. Identification and concentrations of VFA peaks were based on a purchased external standard from Sigma Chemical Co. (St. Louis, MO).

Rumen LIQ and SOL samples were frozen and lyophilized before long-chain FA analysis. All LIQ and SOL samples were ground by mortar and pestle to maximize sample recovery and refrozen until FA analysis. Before analysis by GLC, rumen FA isolation and methylation followed the procedure by Sukhija and Palmquist (1988) with one exception: the average sample size increased from 0.3 to $0.7 \mathrm{~g}$ to increase the amount of $\mathrm{FA}$ injected into the GLC. Nonadecanoic acid, C19:0, was added as an internal standard at a precisely known amount that ranged from 4.000 to $4.022 \mathrm{mg} / \mathrm{sample}$. The column and temperature program used to run rumen FAME 
Table 2. Dry matter intake during infusion and concentrations of glucose, NEFA, BHBA, insulin, and VFA at $0 \mathrm{~h}$ and at the end of 18-h infusion

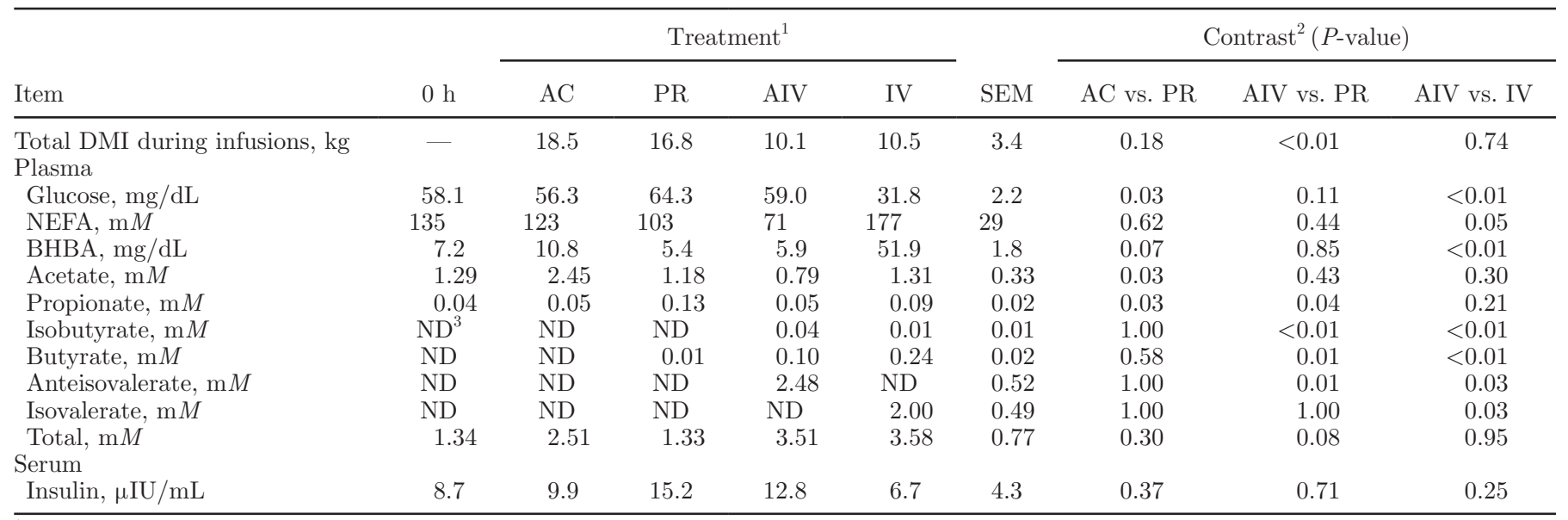

${ }^{1}$ Infusion treatments: $\mathrm{AC}=$ acetate, $\mathrm{PR}=$ propionate, $\mathrm{AIV}=$ anteisovalerate, $\mathrm{IV}=$ isovalerate.

${ }^{2}$ Preplanned contrasts: negative vs. positive control (AC vs. PR); glucogenic precursors (AIV vs. PR); glucogenic vs. ketogenic precursor (AIV vs. IV).

${ }^{3} \mathrm{ND}=$ not detected in sample.

was the same as reported for feed FA. Helium was used as the carrier gas. Peaks were identified using the same standards as for feed FAME. Total unknown FA were summed from C14:0 to C24:1.

\section{Milk Sampling and Analysis}

In each period, relative to the start of infusions $(0$ $\mathrm{h}$ ), individual p.m. and a.m. milk samples were collected at 11.5, 23.5, 35.5, and $47.5 \mathrm{~h}$ and divided into 2 subsamples ( $\mathrm{n}=4$ sample pairs/cow per period). One subsample was analyzed for fat, protein, lactose, SNF, SCC, and MUN. Daily milk component production and composition was determined from the composition of these individual samples and the yield for each milking. The milk samples in the second set were immediately composited by cow and period based on milk volume produced at each milking. The milk fat was isolated from the composited sample and analyzed for relative proportions of individual FA.

Individual milking samples were sent to AgSource Milk Analysis Laboratory (Menomonie, WI) for analysis of the percentage milk fat, protein, lactose, SNF, MUN, and SCC. Percentages of fat, true protein, lactose, and MUN were determined by infrared analysis using a Foss FT6000 instrument. Somatic cell count was determined with a Foss 400 instrument (Foss Electric, Hillerød, Denmark) according to AOAC (2006). The composited milk samples were centrifuged for milk fat isolation (Hara and Radin, 1978). Isolated milk fat was methylated and prepared for GLC analysis of individual known and unknown FA from C4:0 to C24:1 (Chouinard et al., 1999). Milk fat samples were analyzed on a PerkinElmer Clarus 500 with the same column and temperature program used for rumen FA analysis. Helium was used as the carrier gas. Using a certified butter oil standard, response factors were calculated and used to adjust peak areas to mass amounts. Based on response factors, unknowns were grouped: C4:0-C6:0, C6:0-C10:0, C10:0-C14:0, C14:0-C18:0, and $>$ C18:0. The same standards used for feed and rumen FAME were used to identify milk FAME. Milk FA production $(\mathrm{g} / \mathrm{d})$ was estimated based on Glasser et al. (2007), who determined that $93.3 \%$ of total milk lipids are triglyceride FA.

\section{Statistical Analysis}

Data on DMI, blood parameters, milk production, milk FA proportions, and milk FA production measured

Table 3. Rumen VFA concentrations and $\mathrm{pH}$ at the termination of 18-h infusions

\begin{tabular}{lccccc}
\hline & \multicolumn{5}{c}{ Treatment $^{1}$} \\
\cline { 2 - 4 } Item & $\mathrm{AC}$ & $\mathrm{PR}$ & $\mathrm{AIV}$ & IV & SEM \\
\hline VFA, mM & & & & & \\
Acetate & $115.2^{\mathrm{a}}$ & $72.7^{\mathrm{b}}$ & $61.0^{\mathrm{b}}$ & $53.9^{\mathrm{b}}$ & 9.6 \\
Propionate & $23.0^{\mathrm{b}}$ & $49.6^{\mathrm{a}}$ & $18.9^{\mathrm{b}}$ & $15.2^{\mathrm{b}}$ & 2.6 \\
Isobutyrate & 1.1 & $1.1^{\mathrm{n}}$ & 1.6 & 1.3 & 0.1 \\
Butyrate & 13.3 & $12.0^{\mathrm{b}}$ & 11.5 & 10.8 & 1.6 \\
Anteisovalerate & $1.0^{\mathrm{b}}$ & $1.2^{\mathrm{b}}$ & $68.5^{\mathrm{a}}$ & $1.2^{\mathrm{b}}$ & 9.9 \\
Isovalerate & $1.1^{\mathrm{b}}$ & $0.8^{\mathrm{b}}$ & $1.1^{\mathrm{b}}$ & $63.0^{\mathrm{a}}$ & 10.7 \\
Valerate & 1.5 & 2.3 & 1.6 & 1.4 & 0.3 \\
Total & 156.1 & 139.7 & 164.1 & 145.8 & 16.3 \\
pH & 6.40 & 6.54 & 6.76 & 6.76 & 0.09 \\
\hline
\end{tabular}

${ }^{\mathrm{a}, \mathrm{b}}$ Means within a row not sharing a common superscript differ $(P<$ $0.05)$.

${ }^{1}$ Infusion treatments: $\mathrm{AC}=$ acetate, $\mathrm{PR}=$ propionate, $\mathrm{AIV}=$ anteisovalerate, $\mathrm{IV}=$ isovalerate. 
variables were analyzed using the MIXED procedure of SAS (SAS Institute, 2001). Analysis followed the model

$$
Y_{i j k}=\mu+T_{i}+P_{j}+C_{k}+e_{i j k},
$$

where $Y_{i j k}=$ dependent variable; $\mu=$ overall least squares means; $T_{i}=$ fixed effect of treatment; $P_{j}=$ fixed effect of period; $C_{k}=$ random effect of cow; and $e_{i j k}=$ random residual error. Following a Tukey adjustment, least squares means were compared for milk FA, rumen VFA, rumen $\mathrm{pH}$, milk production, and milk composition. The ratio of milk C17:0 to C15:0 was also calculated across treatments as an indicator of energy status. Based on findings by Craninx et al. (2008), the ratio of milk C17:0 to C15:0 proportions increased during early lactation and this increase was attributed to animals being in negative energy balance. Rumen FA proportions were analyzed using a similar model with the addition of phase (LIQ and SOL) as a fixed effect. Least squares means were compared after a Tukey adjustment. Three preplanned, single degree of freedom contrasts were analyzed for DMI and 18-h blood measurements: the positive control, $\mathrm{AC}$ versus $\mathrm{PR}$; the glucogenic VFA, PR versus AIV; and the contrast between isoenergetic and isomolar solutions, AIV versus IV. Compared with AC, infusing PR was expected to reduce DMI, increase insulin and glucose, and decrease BHBA and NEFA (Sheperd and Combs, 1998; Oba and Allen, 2003). Because PR and AIV are glucogenic, infusion of either was expected to yield similar responses (Gropper et al., 2005). The comparison between AIV and IV was expected to be similar to that between AC and PR, where one treatment is glucogenic and the other is not.

\section{RESULTS AND DISCUSSION}

\section{Diet Chemical Composition}

Analyzed chemical composition of the diet was as anticipated except for dietary CP that averaged $150 \mathrm{~g} /$ $\mathrm{kg}$ of TMR DM, which was less than intended (Table 1). Dietary CP appeared to be adequate based on average daily MUN concentrations that were in the recommended range of 8.5 to $11.5 \mathrm{mg} / \mathrm{dL}$ (Kohn et al., 2002). The TMR contained measurable amounts of the OBCFA C13:0, iso C15:0, C15:0, iso C17:0, and C17:0 (Table 1).

\section{DMI and Blood Measurements}

Total DMI were different than expected (Table 2). During the infusion period, based on an estimated ME content of $1.57 \mathrm{Mcal} / \mathrm{kg}$ of TMR DM and the heats of combustion for the VFA, total ME consumption for DMI plus infusates was 33.14, 33.41, 28.74, and 28.86 Mcal/18 h for AC, PR, AIV, and IV. Dry matter intakes between $\mathrm{AC}$ and $\mathrm{PR}$ were not different $(P>0.05)$ at $9.5,13.5,17.5$, or $23 \mathrm{~h}$ (data not shown), or in total for the entire infusion (Table 2). Previously, research suggested that intraruminal infusions of PR into lactating dairy cows depress feed intake relative to isomolar acetate infusions (Sheperd and Combs, 1998; Oba and Allen, 2003). The effect is characterized by decreasing the time to stimulate satiety and has been attributed to increased PR influx into the liver and its rate of utilization for glucose production (Bradford and Allen, 2007). Plasma glucose increased $(P<0.05)$ following PR infusions compared with AC (Table 2).

Because metabolism of AIV, but not IV, produces propionyl-CoA, we expected AIV to decrease DMI more than IV. Although infusing BCVFA decreased DMI, the glucogenic VFA (PR vs. AC; AIV vs. IV) did not result in any additional reduction in DMI at each time point (data not shown) or during the entire infusion (Table 2). The decreased DMI due to infusing AIV and IV is most likely due to the large amount infused, as rumen concentrations of either VFA are typically less than $5 \%$ of the concentrations we attained from infusions.

Despite the similarity in DMI and energy intake between AIV and IV, infusing IV drastically decreased $(P<0.05)$ blood glucose, and NEFA and BHBA increased compared with AIV. The blood measurement results support the glucogenic properties of AIV and the ketogenic properties of IV (Menahan and Schultz, 1964; Gropper et al., 2005). Blood insulin was not significantly different for any comparison, but the pattern was consistent with increased body fat mobilization and decreased glucose concentration during IV infusion. Increased plasma BHBA from infusing IV was observed previously when fasted goats were dosed with $0.2 \mathrm{~mol}$ IV intraruminally by ruminal puncture (Menahan and Schultz, 1964). In addition to hepatic metabolism of NEFA, the increased BHBA from IV infusions could result from metabolism of IV by the rumen epithelium, which was previously measured to metabolize approximately $50 \%$ of the infused IV in the washed rumen of steers (Kristensen and Harmon, 2004b). Metabolism of IV by the liver would also support increases in plasma BHBA concentrations.

Plasma VFA concentrations across treatments were as expected (Table 2). Cows had the greatest $(P<$ 0.05) plasma concentration of the VFA present in the infusate in all preplanned contrasts. Plasma isobutyrate was greater $(P<0.05)$ after AIV infusions compared with IV and PR infusions (Table 2). The increase in isobutyrate from AIV is contrary to previous research 
where incubating IV with rumen epithelium slices increased the concentration of isobutyrate in vitro (Annison and Pennington, 1954).

Concentrations of plasma butyrate were greater $(P$ $<0.05)$ for IV compared with AIV, and for AIV ( $P$ $<0.05$ ) compared with PR (Table 2). The concentration of rumen butyrate was not different across treatments. Infusing AIV tended $(P<0.10)$ to increase the total concentration of blood VFA compared with PR. In sheep and steers, intraruminally infusing VFA mixtures (Kristensen et al., 1998) or increasing amounts of butyrate (Kristensen and Harmon, 2004a) reduced the hepatic extraction of VFA from the portal vein, particularly PR and butyrate, and increased the supply of VFA to the periphery. Individually infusing AIV or IV may have elicited a similar reduction in hepatic extraction of butyrate.

\section{Rumen pH, VFA, and Individual FA}

Rumen $\mathrm{pH}$ measured at the end of the infusion period was similar among treatments (Table 3). Measured rumen VFA concentrations across treatments were as expected (Table 3$)$. Cows had the greatest $(P<0.05)$ rumen concentration of the VFA present in the infusate. Valerate concentration was greatest during PR infusion, as valerate can be formed via condensation of PR with acetyl-CoA (Wiltrout and Satter, 1972).

Total FA (g/kg of rumen contents) were greater in LIQ and SOL after PR infusions. Although the observed differences were minor given the amount of AIV infused, infusing AIV resulted in greater $(P<0.05)$ proportion of rumen SOL anteiso $\mathrm{C} 15: 0$ and anteiso C17:0 (Table 4). Infusing IV also increased $(P<0.05)$ the proportion of iso C15:0 in SOL. Overall, detectable FA in rumen SOL and LIQ were minimally altered following infusion.

Other observed differences in FA profiles were minimal; therefore, the least squares means by rumen phase were reported (Table 5). Proportions of SOL and LIQ C13:0 were lowest $(P<0.05)$ after AIV infusions compared with other treatments, whereas AIV ranked greatest $(P<0.05)$ in the concentration of SOL cis-9, trans-11 conjugated linoleic acid (CLA) compared with other treatments (0.131 vs. $0.092 \mathrm{~g} / 100 \mathrm{~g}$ of total FA). Infusing IV sustained greater $(P<0.05)$ proportions of SOL iso C14:0 compared with PR. In vitro, mixed rumen bacteria incorporated $\left[1-\mathrm{C}^{14}\right]$ isobutyrate into even and odd iso FA (Tweedie et al., 1966). The increase in iso C14:0 following IV infusions in the current study may indicate the ability of rumen microorganisms to incorporate IV into even iso FA.

In the current study, the lack of increase in proportions of FA in rumen LIQ and SOL following the infu- sion of the corresponding VFA precursor suggests the inability for individual species of bacteria to alter their FA composition based on the presence of VFA precursors. Previously in vitro, incubating Fibrobacter succinogenes with or without a mixture of VFA containing $0.44 M$ butyrate, $0.11 M$ IB, $0.092 M$ AIV, and 0.092 $M$ IV led to minor changes in OBCFA profiles (Saluzzi et al., 1993). Incubating pure cultures with sodium [1$\left.\mathrm{C}^{14}\right] \mathrm{IV}$ also demonstrated the ability of some species to incorporate over $74 \%$ of IV into iso C15:0 FA. Other species had the inability to incorporate IV into FA or grow in medium containing IV. Species that reportedly could not use IV, including strains of Ruminococcus albus and Bacteroides succinogenes, have the ability to use other BCVFA for FA synthesis and growth (Allison et al., 1962; Dehority et al., 1967). Aside from synthesizing branched-chain FA, incubating pure cultures with BCVFA also demonstrated the ability of bacteria to synthesize a variety of branched-chain compounds including multiple methyl-branched FA, AA, and aldehydes that were not measured in the current study (Bryant and Doetsch, 1955; Allison et al., 1962; Wegner and Foster, 1963; Dehority et al., 1967). Past research has demonstrated differences in OBCFA proportions between rumen microbial species and within species based on the substrate provided. Research with pure strains of rumen microbes suggest the former is much more likely to contribute to altered microbial OBCFA than the latter.

Expressed as g/100 $\mathrm{g}$ of total FA, rumen LIQ had greater $(P<0.05) \mathrm{C} 13: 0, \mathrm{C} 17: 0, \mathrm{C} 17: 1$, and even iso $\mathrm{FA}$, and lower proportions of $\mathrm{C} 15: 0$, anteiso $\mathrm{C} 15: 0$, and iso $\mathrm{C} 17$ than SOL (Table 4). Culturable amylolytic bacterial species, considered to be liquid associated, including Selenomonas ruminantium, Streptococcus bovis, and Ruminobacter amylophilus, had the majority of their total FA represented by linear odd-chain FA, C13:0, C15:0, C17:0, and C17:1, whereas pure cultures of cellulolytic bacteria, considered to reside in the solid fraction of the rumen, had greater proportions of even iso FA and iso C17:0 compared with amylolytic bacteria (Ifkovits and Ragheb, 1968; Minato et al., 1988; Saluzzi et al., 1993). When feeding diets with varying forage to concentrate ratios, linear odd-chain $\mathrm{FA}$ and anteiso C15:0 were consistently greater, and iso C17:0 lower, in liquid-associated bacteria compared with solid-associated bacteria (Vlaeminck et al., 2006b). Increasing the proportion of concentrates in lactating cow diets also increased duodenal flows of anteiso C15:0 (Dewhurst et al., 2007). Feeding increasing levels of forage in goat diets resulted in an increased proportion of microbial even iso FA in the duodenal digesta (Bas et al., 2003). The proportions of $\mathrm{C} 13: 0$, iso $\mathrm{C} 17: 0, \mathrm{C} 17: 0$, and $\mathrm{C} 17: 1$ in our LIQ and SOL rumen fractions are consistent with 
Table 4. Proportions (g/100 g of FA, unless otherwise noted) of odd- and branched-chain FA and even-chain FA in rumen liquid and solid phases at termination of 18 -h infusions

\begin{tabular}{|c|c|c|c|c|c|}
\hline \multirow[b]{2}{*}{ Item } & \multicolumn{4}{|c|}{ Treatment $^{1}$} & \multirow[b]{2}{*}{ SEM } \\
\hline & $\mathrm{AC}$ & PR & AIV & IV & \\
\hline \multicolumn{6}{|c|}{ Rumen liquid phase } \\
\hline Total FA, $\mathrm{g} / \mathrm{kg}$ & 42.9 & 62.8 & 32.3 & 30.3 & 55 \\
\hline C13:0 & $0.35^{\mathrm{ab}}$ & $0.43^{\mathrm{a}}$ & $0.05^{\mathrm{b}}$ & $0.51^{\mathrm{a}}$ & 0.08 \\
\hline Iso $\mathrm{C} 14: 0$ & 0.85 & 0.63 & 0.89 & 1.34 & 0.37 \\
\hline Iso C15:0 & 0.21 & 0.28 & 0.42 & 0.37 & 0.08 \\
\hline Anteiso C15:0 & 0.16 & 0.12 & 0.35 & 0.12 & 0.07 \\
\hline C15:0 & 0.34 & 0.39 & 0.51 & 0.35 & 0.07 \\
\hline Iso C16:0 & 1.68 & 1.94 & 1.46 & 1.61 & 0.21 \\
\hline Iso C17:0 & 0.03 & 0.03 & 0.11 & 0.01 & 0.03 \\
\hline Anteiso C17:0 & 0.07 & 0.07 & 0.17 & 0.07 & 0.04 \\
\hline C17:0 & 0.80 & 0.60 & 1.42 & 1.05 & 0.23 \\
\hline $\mathrm{C} 17: 1$ & 0.29 & 0.26 & 0.19 & 0.19 & 0.04 \\
\hline C6:0 & 2.97 & 2.57 & 3.04 & 4.26 & 0.63 \\
\hline C8:0 & 0.023 & 0.015 & 0.017 & 0.023 & 0.008 \\
\hline C10:0 & $\mathrm{ND}^{2}$ & 0.002 & 0.003 & ND & 0.001 \\
\hline C12:0 & 0.04 & 0.03 & 0.06 & 0.02 & 0.02 \\
\hline C16:0 & 13.79 & 16.24 & 17.20 & 16.01 & 1.22 \\
\hline C18:0 & 50.21 & 54.88 & 48.96 & 51.49 & 1.51 \\
\hline \multicolumn{6}{|c|}{ Rumen solid phase } \\
\hline Total FA, g/kg & 47.3 & 51.1 & 49.2 & 50.8 & 9 \\
\hline $\mathrm{C} 13: 0$ & $0.11^{\mathrm{a}}$ & $0.14^{\mathrm{a}}$ & $0.05^{\mathrm{b}}$ & $0.15^{\mathrm{a}}$ & 0.01 \\
\hline Iso C14:0 & $0.25^{\mathrm{ab}}$ & $0.20^{\mathrm{b}}$ & $0.30^{\mathrm{ab}}$ & $0.36^{\mathrm{a}}$ & 0.05 \\
\hline Iso C15:0 & $0.25^{\mathrm{b}}$ & $0.23^{\mathrm{b}}$ & $0.19^{\mathrm{b}}$ & $0.34^{\mathrm{a}}$ & 0.02 \\
\hline Anteiso C15:0 & $0.43^{\mathrm{b}}$ & $0.45^{\mathrm{b}}$ & $0.58^{\mathrm{a}}$ & $0.42^{\mathrm{b}}$ & 0.03 \\
\hline $\mathrm{C} 15: 0$ & 0.52 & 0.62 & 0.56 & 0.55 & 0.03 \\
\hline Iso C16:0 & 0.67 & 0.62 & 0.54 & 0.55 & 0.04 \\
\hline Iso $\mathrm{C} 17: 0$ & 0.15 & 0.13 & 0.16 & 0.16 & 0.05 \\
\hline Anteiso C17:0 & $0.13^{\mathrm{b}}$ & $0.11^{\mathrm{b}}$ & $0.21^{\mathrm{a}}$ & $0.13^{\mathrm{b}}$ & 0.01 \\
\hline C17:0 & $0.48^{\mathrm{b}}$ & $0.59^{\mathrm{a}}$ & $0.57^{\mathrm{a}}$ & $0.58^{\mathrm{a}}$ & 0.03 \\
\hline $\mathrm{C} 17: 1$ & 0.17 & 0.14 & 0.17 & 0.15 & 0.02 \\
\hline C6:0 & 0.58 & 0.44 & 0.42 & 0.49 & 0.08 \\
\hline C8:0 & 0.018 & 0.021 & 0.015 & 0.025 & 0.004 \\
\hline C10:0 & 0.016 & 0.004 & 0.052 & 0.019 & 0.016 \\
\hline C12:0 & 0.15 & 0.15 & 0.14 & 0.13 & 0.01 \\
\hline C16:0 & 21.59 & 21.79 & 22.03 & 21.82 & 0.30 \\
\hline C18:0 & 33.35 & 37.02 & 36.14 & 36.02 & 1.22 \\
\hline
\end{tabular}

a,b Means within a row not sharing a common superscript differ $(P<0.05)$.

${ }^{1}$ Infusion treatments: $\mathrm{AC}=$ acetate, $\mathrm{PR}=$ propionate, $\mathrm{AIV}=$ anteisovalerate, $\mathrm{IV}=$ isovalerate.

${ }^{2} \mathrm{ND}=$ not detected in sample.

the FA found in the pure or washed microbes associated with those phases in previous literature; however, proportions of $\mathrm{C} 15: 0$, even iso $\mathrm{FA}$, and anteiso $\mathrm{C} 15: 0$ were inconsistent with previous findings.

The proportion of iso C15:0 was similar between LIQ and SOL. Previous studies have demonstrated mixed results. Incubating fresh herbage in situ increased iso C15:0 in liquid-associated bacteria (Kim et al., 2005), whereas greater iso C15:0 has also been observed in pure cultures of cellulolytic bacteria compared with amylolytic (Ifkovits and Ragheb, 1968; Minato et al., 1988; Saluzzi et al., 1993).

Despite the observed treatment differences, proportions of individual OBCFA within rumen phases did not always seem to differ greatly from the proportion of dietary OBCFA (Table 1, Table 4). In particular rumen $\mathrm{C} 13: 0$, iso $\mathrm{C} 15: 0$, iso $\mathrm{C} 17: 0$, and $\mathrm{C} 17: 1$ were not consistently greater than their proportions in the TMR and, in several cases, were less.

Other reported rumen OBCFA proportions were noticeably greater compared with dietary values. Similar to the current study, a variety of feedstuffs including fermented feeds, concentrate mixtures and fresh grasses have previously been reported to contain OBCFA. However, in most previous research, the proportion of OBCFA measured in rumen or duodenal contents are greater than feed OBCFA (Bauchart et al., 1990; Kim et al., 2005; Dewhurst et al., 2007). Other research comparing effects of forage to concentrate ratio, the type of forage fed and inclusion level, and addition of other 
Table 5. Least squares means of major fatty acids in rumen liquid and solid phases

\begin{tabular}{lcccr}
\hline & \multicolumn{2}{c}{ Phase } & & \\
\cline { 2 - 3 } FA, g/100 g & Liquid & Solid & SEM & P-value \\
\hline Cf total FA & 0.40 & 0.07 & 0.03 & $<0.001$ \\
C9:0 & 0.16 & 0.05 & 0.05 & 0.041 \\
C10:1 & 0.002 & 0.015 & 0.004 & 0.002 \\
C14:0 & 0.33 & 0.84 & 0.04 & $<0.001$ \\
C14:1 cis-9 & 0.07 & 0.06 & 0.02 & 0.559 \\
C15:1 & 0.007 & 0.03 & 0.009 & 0.007 \\
C16:1 cis-9 & 0.04 & 0.20 & 0.01 & $<0.001$ \\
C18:1 total & 12.20 & 15.74 & 0.41 & $<0.001$ \\
C18:2 cis-9, cis-12 & 2.88 & 16.55 & 0.48 & $<0.001$ \\
C20:0 & 0.06 & 0.23 & 0.04 & $<0.001$ \\
C20:1 & 0.03 & 0.16 & 0.04 & 0.005 \\
C18:3 cis-9, cis-12,cis-15 & 1.11 & 1.71 & 0.13 & $<0.001$ \\
CLA ${ }^{1}$ cis-9,trans-11 & 0.03 & 0.10 & 0.01 & $<0.001$ \\
CLA trans-10, cis-12 & 0.03 & 0.05 & 0.01 & 0.397 \\
C21:0 & 0.17 & 0.07 & 0.03 & $<0.001$ \\
C20:3 n-9 & 0.04 & 0.04 & 0.03 & 0.916 \\
C22:0 & 0.10 & 0.50 & 0.03 & $<0.001$ \\
C24:0 & 0.10 & 0.47 & 0.05 & $<0.001$ \\
C22:6 & 0.02 & 0.04 & 0.02 & 0.221 \\
Unknowns, C14:0-C22:6 & 7.18 & 1.66 & 0.75 & $<0.001$ \\
\hline
\end{tabular}

${ }^{1}$ Conjugated linoleic acid.

dietary ingredients have not reported feed OBCFA or none were detected (Bas et al., 2003; Vlaeminck et al., 2006b; Boeckaert et al., 2008).

\section{Milk Production, Milk Composition, and Milk FA}

No differences $(P>0.05)$ were observed across treatments for milk production and milk yield or concentrations of fat, protein, and lactose (Table 6). While receiving the PR treatment, one cow had a markedly increased milk fat concentration at the first 2 milkings during the experimental period $(11.64,5.45,4.50$, and $4.35 \%$ at $11.5,23.5,35.5$, and $47.5 \mathrm{~h}$; Table 6 ).

Milk FA patterns were minimally affected by VFA infusion treatments, and no differences were detected for milk FA yield (Table 7). Only OBCFA and evenchain FA data are presented. Infusing PR led to the greatest $(P<0.05)$ concentration of $\mathrm{C} 15: 0$ and $\mathrm{C} 17: 0$ in milk fat (Table 7). This increase in odd-chain FA was the only expected difference detected. Results indicate de novo synthesis from propionyl-CoA in the mammary gland because infusing PR did not increase proportions of odd-chain FA in the rumen, whereas blood PR increased and odd-chain FA proportions in milk increased. Similarly, previous work found that milk yields of $\mathrm{C} 15: 0$ and $\mathrm{C} 17: 0$ were greater than duodenal yields, implying postabsorptive synthesis of odd-chain FA (Dewhurst et al., 2007). Indeed, earlier studies demonstrated that perfusing goat and cow udders with labeled PR increased milk linear odd-chain

Table 6. Milk production and composition

\begin{tabular}{|c|c|c|c|c|c|}
\hline \multirow[b]{2}{*}{ Item } & \multicolumn{4}{|c|}{ Treatment $^{1}$} & \multirow[b]{2}{*}{ SEM } \\
\hline & $\mathrm{AC}$ & $\mathrm{PR}$ & AIV & IV & \\
\hline \multicolumn{6}{|l|}{ Milk production } \\
\hline Milk, $\mathrm{kg} / \mathrm{d}$ & 32.8 & 33.9 & 24.9 & 25.0 & 5.0 \\
\hline $3.5 \% \mathrm{FCM}, \mathrm{kg} / \mathrm{d}$ & 33.0 & 42.8 & 27.0 & 26.1 & 7.8 \\
\hline Fat, $\mathrm{g} / \mathrm{d}$ & 1,164 & 1,736 & 1,001 & 947 & 376 \\
\hline Protein, g/d & 978 & 1,029 & 759 & 770 & 156 \\
\hline Lactose, $\mathrm{g} / \mathrm{d}$ & 1,599 & 1,621 & 1,210 & 1,207 & 242 \\
\hline SNF & 2,869 & 2,962 & 2,198 & 2,203 & 441 \\
\hline \multicolumn{6}{|l|}{ Milk composition, $\%$} \\
\hline Fat, $\%$ & 3.60 & 4.78 & 3.96 & 3.71 & 0.69 \\
\hline Protein, \% & 2.99 & 3.04 & 3.02 & 3.04 & 0.10 \\
\hline Lactose, \% & 4.87 & 4.80 & 4.87 & 4.83 & 0.07 \\
\hline MUN, mg/dL & 10.1 & 8.9 & 11.2 & 11.0 & 0.8 \\
\hline $\mathrm{SCC}, \times 1,000$ cells $/ \mathrm{mL}$ & 208 & 71 & 37 & 62 & 66 \\
\hline
\end{tabular}

${ }^{1}$ Infusion treatments: $\mathrm{AC}=$ acetate, $\mathrm{PR}=$ propionate, $\mathrm{AIV}=$ anteisovalerate, $\mathrm{IV}=$ isovalerate. 
FA proportions resulting from de novo synthesis (James et al., 1956; Massart-Leën et al., 1983; Emmanuel and Kennelly, 1985).

In milk fat, infusing IV resulted in the greatest $(P<$ 0.05) concentration of $\mathrm{C} 6: 0, \mathrm{C} 8: 0, \mathrm{C} 10: 0, \mathrm{C} 12: 0, \mathrm{C} 18: 0$, and the lowest concentration of C16:0 (Table 7). This treatment effect was not observed in rumen LIQ and SOL FA. Blood BHBA is a precursor for de novo synthesis of short- and medium-chain FA in the mammary gland (Bauman and Davis, 1974); therefore, the drastic increase in blood BHBA during IV infusions may have increased synthesis of these milk FA by mass action.

During times of negative energy balance and elevated NEFA, cows have demonstrated increased proportions of C18:0 in milk fat that may arise from C18:0 mobilized from adipose stores (Clarke, 1993; Stoop et al., 2009). The animals receiving IV in the current experi- ment had elevated NEFA that could contribute to milk C18:0. In addition, animals dropped an average of 33 $\pm 27 \mathrm{~kg}$ of BW throughout the trial (data not shown). Increased milk C17:0 to C15:0 ratio observed at the onset of lactation were attributed to mobilization of body stores during negative energy balance (Craninx et al., 2008). In the current study, period had no effect on the concentration of milk C17:0 or other OBCFA as animals were in mid lactation and the trial was very short. Long-chain FA have previously been related to energy balance of dairy cows (Van Haelst et al., 2008). Milk proportions of C18:1 cis-9 and total long-chain FA were elevated 2 wk before cows were diagnosed with subclinical ketosis (Van Haelst et al., 2008). Plasma NEFA was greatest during IV infusions, and the ratio of milk C17:0 to C15:0 was 0.44 for IV compared with 0.39 or less for other treatment (Table 7 ). Odd anteiso

Table 7. Milk proportions ( $\mathrm{g} / 100 \mathrm{~g}$ of FA) and secretion $(\mathrm{g} / \mathrm{d})$ of odd- and branched-chain FA and even-chain FA during the 2-d experimental period

\begin{tabular}{|c|c|c|c|c|c|}
\hline \multirow[b]{2}{*}{ Item } & \multicolumn{4}{|c|}{ Treatment $^{1}$} & \multirow[b]{2}{*}{ SEM } \\
\hline & $\mathrm{AC}$ & PR & AIV & IV & \\
\hline \multicolumn{6}{|c|}{ Proportion, g/100 g of FA } \\
\hline C13:0 & 0.08 & 0.10 & 0.11 & 0.08 & 0.01 \\
\hline Iso C14:0 & 0.13 & 0.14 & 0.13 & 0.14 & 0.01 \\
\hline Iso C15:0 & 0.18 & 0.19 & 0.18 & 0.20 & 0.01 \\
\hline Anteiso C15:0 & 0.41 & 0.42 & 0.44 & 0.41 & 0.02 \\
\hline C15:0 & $1.03^{\mathrm{b}}$ & $1.37^{\mathrm{a}}$ & $1.21^{\mathrm{ab}}$ & $1.00^{\mathrm{b}}$ & 0.08 \\
\hline Iso C16:0 & 0.27 & 0.26 & 0.24 & 0.27 & 0.02 \\
\hline Iso C17:0 & 0.12 & 0.13 & 0.13 & 0.14 & 0.01 \\
\hline Anteiso C17:0 & 0.26 & 0.26 & 0.27 & 0.26 & 0.02 \\
\hline $\mathrm{C} 17: 0$ & $0.44^{\mathrm{b}}$ & $0.51^{\mathrm{a}}$ & $0.48^{\mathrm{ab}}$ & $0.47^{\mathrm{ab}}$ & 0.03 \\
\hline C17:1 & 0.17 & 0.15 & 0.17 & 0.15 & 0.01 \\
\hline $\mathrm{C} 17: 0$ to $\mathrm{C} 15: 0$ & 0.39 & 0.38 & 0.39 & 0.44 & 0.03 \\
\hline C6:0 & $2.08^{\mathrm{b}}$ & $2.08^{\mathrm{b}}$ & $2.33^{\mathrm{ab}}$ & $2.64^{\mathrm{a}}$ & 0.12 \\
\hline $\mathrm{C} 8: 0$ & $1.65^{\mathrm{b}}$ & $1.53^{\mathrm{b}}$ & $1.72^{\mathrm{b}}$ & $2.20^{\mathrm{a}}$ & 0.09 \\
\hline $\mathrm{C} 10: 0$ & $2.61^{\mathrm{b}}$ & $2.37^{\mathrm{b}}$ & $2.68^{\mathrm{b}}$ & $3.31^{\mathrm{a}}$ & 0.16 \\
\hline $\mathrm{C} 12: 0$ & $2.85^{\mathrm{ab}}$ & $2.61^{\mathrm{b}}$ & $2.90^{\mathrm{ab}}$ & $3.42^{\mathrm{a}}$ & 0.18 \\
\hline C16:0 & $31.05^{\mathrm{a}}$ & $30.11^{\mathrm{a}}$ & $29.49^{\mathrm{ab}}$ & $28.06^{\mathrm{b}}$ & 1.01 \\
\hline C18:0 & $11.69^{\mathrm{ab}}$ & $11.30^{\mathrm{b}}$ & $11.30^{\mathrm{b}}$ & $13.16^{\mathrm{a}}$ & 0.66 \\
\hline $\mathrm{C} 18: 0$ to $\mathrm{C} 14: 0$ & 1.11 & 1.22 & 1.20 & 1.26 & 0.09 \\
\hline \multicolumn{6}{|l|}{ Secretion, ${ }^{2} \mathrm{~g} / \mathrm{d}$} \\
\hline $\mathrm{C} 13: 0$ & 1.0 & 1.5 & 1.3 & 1.1 & 0.3 \\
\hline Iso C14:0 & 1.5 & 2.3 & 1.3 & 1.9 & 0.6 \\
\hline Iso C15:0 & 2.0 & 3.0 & 1.5 & 2.3 & 0.7 \\
\hline Anteiso C15:0 & 4.3 & 6.3 & 4.0 & 4.0 & 1.2 \\
\hline C15:0 & 11.8 & 20.8 & 12.5 & 11.2 & 4.7 \\
\hline Iso C16:0 & 2.8 & 4.3 & 2.3 & 3.6 & 1.1 \\
\hline Iso C17:0 & 1.0 & 2.3 & 1.5 & 1.4 & 0.6 \\
\hline Anteiso C17:0 & 2.8 & 4.0 & 2.3 & 2.4 & 0.8 \\
\hline $\mathrm{C} 17: 0$ & 4.3 & 8.0 & 4.8 & 4.5 & 1.7 \\
\hline C17:1 & 1.3 & 2.3 & 1.5 & 1.2 & 0.5 \\
\hline C6:0 & 22.9 & 21.9 & 20.1 & 23.7 & 4.9 \\
\hline C8:0 & 17.1 & 15.6 & 14.5 & 19.3 & 3.6 \\
\hline C10:0 & 27.1 & 23.9 & 22.7 & 29.5 & 5.5 \\
\hline C12:0 & 29.6 & 25.9 & 24.7 & 30.6 & 5.7 \\
\hline C16:0 & 326.7 & 507.8 & 267.5 & 326.7 & 135.1 \\
\hline C18:0 & 117.5 & 175.3 & 105.3 & 108.3 & 35.6 \\
\hline
\end{tabular}


and iso FA proportions and yield in milk fat were minimally altered after AIV and IV infusions. Although the mammary gland is capable of synthesizing odd-chain FA from PR, minimal synthesis of branched-chain FA from IV and AIV has been reported previously (Verbeke et al., 1959; Croom et al., 1981). The data presented suggest minimal de novo synthesis of milk branched-chain FA based on the resulting increased blood AIV and IV after infusions and the lack of response in milk odd anteiso and iso FA. Alternatively, AIV and IV could have been used by the mammary gland to increase free pools of Ile and Leu. Indeed, Chang et al. (1985) measured an increase in free Ile and Leu when incubating lactating mammary tissue from cows with $10 \mathrm{~m} M$ AIV and IV.

Research has already demonstrated the utility of cellular FA composition in measuring taxonomic differences between genera of bacteria (Moore et al., 1994). In an overview of the literature concerning milk OBCFA, milk OBCFA proportions were correlated $(P$ $<0.05)$ with dietary nutrients including NDF, starch, FA, and CP (Vlaeminck et al., 2006a). Based on in vitro and in vivo studies, rumen shifts in OBCFA are primarily affected by altered populations of different rumen microbial strains driven by dietary composition as opposed to altered VFA available in the extracellular space for FA synthesis (Ifkovits and Ragheb, 1968; Bas et al., 2003; Vlaeminck et al., 2006b). Our data confirm that extracellular VFA concentrations that can serve as primers for synthesis of OBCFA are not a primary cause for the relationship of diet to rumen and milk OBCFA. Relating to rumen microbial variation, the duration of the study was probably too short to allow for microbial population changes.

\section{CONCLUSIONS}

Infusing AIV and IV drastically decreased DMI, but AIV was able to maintain blood metabolites resembling a more neutral energy balance, whereas IV increased the concentration of blood ketones, NEFA, and the proportion of milk even-chain FA. Infusing PR increased blood PR and milk C15:0 and C17:0 without significantly increasing rumen $\mathrm{C} 15: 0$ and $\mathrm{C} 17: 0$. These findings suggest a postabsorptive influence of diets extreme enough to elevate blood PR increase mammary de novo synthesis of odd-chain FA. Despite the amount of BCVFA infused, minimal effects were observed in linear odd-chain FA, odd anteiso, and odd iso FA patterns in rumen LIQ, rumen SOL, and milk fat. In addition, OBCFA proportions did not always differ from dietary OBCFA, particularly C13:0, iso $\mathrm{C} 15: 0$, iso $\mathrm{C} 17: 0$, and C17:1. The lack of difference suggests little exogenous use of VFA for OBCFA production within the rumen or for de novo synthesis in the mammary gland, even if blood concentrations of AIV and IV are elevated. Physiological variations in rumen VFA will not result in drastically altered milk OBCFA proportions; therefore, correlations of rumen VFA and milk FA must be attributed to some other mechanism.

\section{ACKNOWLEDGMENTS}

The authors extend their appreciation to the staff at the University of Wisconsin Dairy Cattle Center for animal care, sample collection, and assistance throughout the experiment. Thanks are also extended to Jake Finer (University of Wisconsin-Madison) for sample preparation for analysis. Funding was provided from Hatch Multistate \#WIS01283.

\section{REFERENCES}

Akashi, S., and K. Saito. 1960. A branched saturated $\mathrm{C}_{15}$ acid (sarcinic acid) from Sarcina phospholipids and a similar acid from several microbial lipids. J. Biochem. 47:222-229.

Allison, M. J., M. P. Bryant, I. Katz, and M. Keeney. 1962. Studies on the metabolic function of branched-chain volatile fatty acids, growth factors for ruminococci. II. Biosynthesis of higher branchedchain fatty acids and aldehydes. J. Bacteriol. 83:1084-1093.

Allison, M. J., and J. L. Peel. 1971. Biosynthesis of valine from isobutyrate by Peptostreptococcus elsdenii and Bacteroides ruminicola. Biochem. J. 121:431-437.

Annison, E. F., and R. J. Pennington. 1954. The metabolism of shortchain fatty acids in the sheep. III Formic, n-valeric and some branched-chain acids. Biochem. J. 57:685-692.

AOAC. 2006. Official Methods of Analysis. 18th ed. AOAC, Gaithersburg, MD.

Bas, P., H. Archimede, A. Rouzeau, and D. Sauvant. 2003. Fatty acid composition of mixed-rumen bacteria: Effect of concentration and type of forage. J. Dairy Sci. 86:2940-2948.

Bauchart, D., F. Legay-Carmier, M. Doreau, and B. Gaillard. 1990. Lipid metabolism of liquid-associated and solid- adherent bacteria in rumen contents of dairy cows offered lipid-supplemented diets. Br. J. Nutr. 63:563-578.

Bauman, D. E., and C. L. Davis. 1974. Biosynthesis of milk fat. Pages 31-75 in Lactation: A Comprehensive Treatise. B. L. Larson and V. R. Smith, ed. Academic Press, New York, NY.

Berthelot, V., P. Bas, P. Schmidely, and C. Duvaux-Ponter. 2001. Effect of dietary propionate on intake patterns and fatty acid composition of adipose tissues in lambs. Small Rumin. Res. 40:29-39.

Bessa, R. J. B., M. R. G. Maia, E. Jerónimo, A. T. Belo, A. R. J. Cabrita, R. J. Dewhurst, and A. J. M. Fonseca. 2009. Using microbial fatty acids to improve understanding of the contribution of solid associated bacteria to microbial mass in the rumen. Anim. Feed Sci. Technol. 150:197-206.

Boeckaert, C., B. Vlaeminck, J. Dijkstra, A. Issa-Zacharia, T. Van Nespen, W. Van Straalen, and V. Fievez. 2008. Effect of dietary starch or micro algae supplementation on rumen fermentation and milk fatty acid composition of dairy cows. J. Dairy Sci. 91:47144727.

Bradford, B. J., and M. S. Allen. 2007. Phlorizin administration does not attenuate hypophagia induced by intraruminal propionate infusion in lactation dairy cattle. J. Nutr. 137:326-330.

Bryant, M. P., and R. N. Doetsch. 1955. Factors necessary for the growth of Bacteroides succinogenes in the volatile acid fraction of rumen fluid. J. Dairy Sci. 38:340-350.

Chang, C. H., E. E. Drury, S. M. Middlebrook, and A. M. Papas. 1985. Effects of branched-chain fatty acids on the metabolism of their respective precursor amino acids in lactating bovine mammary tissue. J. Dairy Sci. 68(Suppl. 1):104-105. (Abstr.) 
Chouinard, P. Y., L. Corneau, A. Sæbø, and D. E. Bauman. 1999 Milk yield and composition during abomasal infusion of conjugated linoleic acids in dairy cows. J. Dairy Sci. 82:2737-2745.

Clarke, S. D. 1993. Regulation of fatty acid synthase gene expression: As approach for reducing fat accumulation. J. Anim. Sci. 71:1957-1965.

Craninx, M., A. Steen, H. Van Laar, T. Van Nespen, J. Martin-Tereso, B. De Baets, and V. Fievez. 2008. Effect of lactation stage on the odd- and branched-chain milk fatty acids of dairy cattle under grazing and indoor conditions. J. Dairy Sci. 91:2662-2677.

Croom, W. J., D. E. Bauman, and C. L. Davis. 1981. Methylmalonic acid in low-fat milk syndrome. J. Dairy Sci. 64:649-654.

Dehority, B. A., H. W. Scott, and P. Kowaluk. 1967. Volatile fatty acid requirements of cellulolytic rumen bacteria. J. Bacteriol 94:537-543.

Dewhurst, R. J., J. M. Moorby, B. Vlaeminck, and V. Fievez. 2007. Apparent recovery of duodenal odd- and branched-chain fatty acids in milk of dairy cows. J. Dairy Sci. 90:1775-1780.

Emmanuel, B. 1978. The relative contribution of propionate, and longchain even-numbered fatty acids to the production of long-chain odd-numbered fatty acids in the rumen. Biochim. Biophys. Acta 528:239-246.

Emmanuel, B., and J. J. Kennelly. 1985. Measures of de novo synthesis of milk components from propionate in lactating goats. J. Dairy Sci. 68:312-319.

Gibbard, S., and P. J. Watkins. 1968. A micro-method for the enzymatic determination of D-beta-hydroxybutyrate and acetoactetate. Clin. Chim. Acta 19:511-521

Glasser, F., M. Doreau, A. Ferlay, and Y. Chilliard. 2007. Technical note: Estimation of milk fatty acid yield from milk fat data. J Dairy Sci. 90:2302-2304.

Gropper, S. S., J. L. Smith, and J. L. Groff. 2005. Page 210 in Advanced Nutrition and Human Metabolism. Thomson Wadsworth Publ., Belmont, CA.

Hara, A., and N. S. Radin. 1978. Lipid extraction of tissues with a low-toxicity solvent. Anal. Biochem. 90:420-426.

Ifkovits, R. W., and H. S. Ragheb. 1968. Cellular fatty acid composition and identification of rumen bacteria. Appl. Microbiol. 16:1406-1413

James, A. T., M. Lauryssens, and G. Peeters. 1956. The metabolism of propionic acid. Biochem. J. 64:726-730.

Kaneda, T. 1991. Iso- and anteiso-fatty acids in bacteria: Biosynthesis, function, and taxonomic significance. Microbiol. Rev. 55:288-302.

Karkalas, J. 1985. An improved enzymatic method for the determination of native and modified starch. J. Sci. Food Agric. 36:10191027.

Keeney, M., I. Katz, and M. J. Allison. 1962. On the probable origin of some milk fat acids in rumen microbial lipids. J. Am. Oil Chem. Soc. 39:198-201.

Kim, E. J., R. Sanderson, M. S. Dhanoa, and R. J. Dewhurst. 2005. Fatty acid profiles associated with microbial colonization of freshly ingested grass and rumen biohydrogenation. J. Dairy Sci. $88: 3220-3230$

Kohn, R. A., K. F. Kalscheur, and E. Russek-Cohen. 2002. Evaluation of models to estimate urinary nitrogen and expected milk urea nitrogen. J. Dairy Sci. 85:227-233.

Kristensen, N. B., A. Danfær, and N. Agergaard. 1998. Short-chain fatty acids in sheep: Portal appearance rates following high intraruminal loads. Acta Agric. Scand. A 48:165-174.

Kristensen, N. B., and D. L. Harmon. 2004a. Effect of increasing ruminal butyrate absorption on splanchnic metabolism of volatile fatty acids absorbed from the washed reticulorumen of steers. J. Anim. Sci. 82:3549-3559.

Kristensen, N. B., and D. L. Harmon. 2004b. Splanchnic metabolism of volatile fatty acids absorbed from the washed reticulorumen of steers. J. Anim. Sci. 82:2033-2042.

Massart-Leën, A. M., E. Roets, G. Peeters, and R. Verbeke. 1983. Propionate for fatty acid synthesis by the mammary gland of the lactating goat. J. Dairy Sci. 66:1445-1454.
Menahan, L. A., and L. H. Schultz. 1964. Effect of leucine and valine on ketogenesis in the ruminant. J. Dairy Sci. 47:1086-1091.

Minato, H., S. Ishibashi, and T. Hamaoka. 1988. Cellular fatty acid and sugar composition of representative strains of rumen bacteria. J. Gen. Appl. Microbiol. 34:303-319.

Moore, L. V. H., D. M. Bourne, and W. E. C. Moore. 1994. Comparative distribution and taxonomic value of cellular fatty acids in thirty-three genera of anaerobic gram-negative bacilli. Int. J. Syst. Bacteriol. 44:338-347.

National Research Council. 2001. Nutrient Requirements of Dairy Cattle. 7th rev. ed. Natl. Acad. Sci., Washington, DC.

Novak, M. 1965. Colometric ultramicro method for the determination of free fatty acids. J. Lipid Res. 6:431-433.

Oba, M., and M. S. Allen. 2003. Dose-response effects of intraruminal infusion of propionate on feeding behavior of lactating cows in early or midlactation. J. Dairy Sci. 86:2922-2931.

Remesy, C., and C. Demigne. 1974. Determination of volatile fatty acids in plasma after ethanolic extraction. Biochem. J. 141:85-91.

Rigout, S., C. Hurtaud, S. Lemosquet, A. Bach, and H. Rulquin. 2003 Lactational effect of propionic acid and duodenal glucose in cows. J. Dairy Sci. 86:243-253.

Saluzzi, L., A. Smith, and C. S. Stewart. 1993. Analysis of bacterial phospholipids markers and plant monosaccharides during forages degradation by Ruminococcus flavefaciens and Fibrobacter succinogenes in co-culture. J. Gen. Microbiol. 139:2865-2873.

SAS Institute. 2001. SAS User's Guide: Statistics. Version 8 ed. SAS Inst. Inc., Cary, NC.

Sheperd, A. C., and D. K. Combs. 1998. Long-term effects of acetate and propionate on voluntary feed intake by midlactation cows. J. Dairy Sci. 81:2240-2250.

Stoop, W. M., H. Bovenhuis, J. M. L. Heck, and J. A. M. van Arendonk. 2009. Effect of lactation stage and energy status on milk fat composition of Holstein-Friesian cows. J. Dairy Sci. 92:1469-1478.

Sukhija, P. S., and D. L. Palmquist. 1988. Rapid method for determination of total fatty acid content and composition of feedstuffs and feces. J. Agric. Food Chem. 36:1202-1206.

Supelco. 1998. Analyzing fatty acids by packed column gas chromatography. Technical bulletin \# 856B. Supelco Inc., Bellefonte, PA.

Tweedie, J. W., M. G. Rumsby, and J. C. Hawke. 1966. Formation of branched long chain fatty acids in cultures of rumen bacteria. J. Sci. Food Agric. 17:241-244.

Van Haelst, Y. N. T., A. Beeckman, A. T. M. Van Knegsel, and V. Fievez. 2008. Short Communication: Elevated concentrations of oleic acid and long-chain fatty acids in milk fat of multiparous subclinical ketotic cows. J. Dairy Sci. 91:4683-4686.

Van Soest, P. J., J. B. Robertson, and B. A. Lewis. 1991. Methods for dietary fiber, neutral detergent fiber, and nonstarch polysaccharides in relation to animal nutrition. J. Dairy Sci. 74:3583-3597.

Verbeke, R., G. M. Lauryssens, G. Peeters, and A. T. James. 1959. Incorporation of DL- $\left[1-{ }^{14} \mathrm{C}\right]$ leucine and $\left[1-{ }^{4} \mathrm{C}\right]$ isovaleric acid into milk constituents by the perfused cow's udder. Biochem. J. 73:24-29.

Vlaeminck, B., V. Fievez, A. R. J. Cabrita, A. J. M. Fonesca, and R. J. Dewhurst. 2006a. Factors affecting odd- and branched-chain fatty acids in milk: A review. Anim. Feed Sci. Technol. 131:389-417.

Vlaeminck, B., V. Fievez, D. Demeyer, and R. J. Dewhurst. 2006b. Effect of forage:concentrate ratio on fatty acid composition of rumen bacteria isolated from ruminal and duodenal digesta. J. Dairy Sci. $89: 2668-2678$

Wegner, G. H., and E. M. Foster. 1963. Incorporation of isobutyrate and valerate into cellular plasmalogen by Bacteroides succinogenes. J. Bacteriol. 85:53-61.

Wiltrout, D. W., and L. D. Satter. 1972. Contribution of propionate to glucose synthesis in lactating and nonlactating cow. J. Dairy Sci. $55: 307-317$. 